\title{
Career Adaptability, Hope, and Life Satisfaction: an Analysis of Adults with and Without Substance Use Disorder
}

\author{
Ilaria Di Maggio ${ }^{1} \cdot$ Esteban Montenegro $^{2} \cdot$ Todd D. Little $^{2} \cdot$ Laura Nota $^{1}$. \\ Maria Cristina Ginevra ${ }^{1}$
}

Accepted: 3 May 2021 / Published online: 28 May 2021

(C) The Author(s) 2021

\begin{abstract}
Considering that adults with Substance Use Disorder (SUD) experience many barriers and challenges in designing and living a satisfactory life, based on Life Design paradigm, this study aimed at analyzing the direct and indirect effect of career adaptability, through hope, on life satisfaction in a sample of individuals with SUD compared to a sample of individuals without SUD. In this study, a sample of 185 adults with and 185 adults without SUD was involved and different measures to assess career adaptability (Career Adapt-Abilities Scale-Italian Form; Soresi, Nota, \& Ferrari; 2012), hope (The Adult Hope Scale) and life satisfaction (The Satisfaction with Life Scale) were used. Multigroup structural analyses were conducted to test the group differences in the direct and indirect effects model hypothesized. Results showed that career adaptability is indirectly, through hope, related to life satisfaction across two groups. These results have important implications for practice and emphasize the need to promoting career adaptability and hope in people with SUD to improve their life satisfaction that is an important diagnostic and outcome criteria in substance use disorder issues.
\end{abstract}

Keywords Life design $\cdot$ Career adaptability $\cdot$ Hope $\cdot$ Life satisfaction $\cdot$ Substance use disorder

\section{Introduction}

The labor participation rate reflects the economic possibility of a country and its tendency to include individuals with vulnerabilities in the job market (Hira-Friesen, 2017). The current social, economic, and political changes have set new challenges in everybody's career planning, especially of individuals with vulnerabilities (e.g. Abkhezr et al., 2017; HiraFriesen, 2017; Wehmeyer et al., 2019). Among individuals with a vulnerability, adults with Substance Use Disorder (SUD) are at high risk to be excluded in the job market and in the social context (e.g., Richardson et al., 2012).

Ilaria Di Maggio

ilaria.dimaggio@unipd.it

1 Universita Degli Studi Di Padova, Padua, Italy

2 Texas Tech University, Lubbock, TX, USA 
Several studies have found that individuals with SUD who actively participate in work and social contexts are more likely have greater therapeutic success, tend to continue the therapeutic path, and have fewer relapses (Richardson et al., 2012; Shepard \& Reif, 2004); therefore, they experience greater feelings of life satisfaction (Foster et al., 2000). In fact, the European Observatory on Drugs $(2013,2017)$ considered both social and job re-integration as fundamental elements of intervention strategies in Substance Use Disorders. Unfortunately, the 2013 report also raised a real alarm about the unemployment rates of individuals with SUD, noting that one in two adults with SUD is unemployed and lives in precarious conditions. These findings are also confirmed in Italy where about the $70 \%$ of individuals in treatment for SUD appear to be unemployed or employed in precarious jobs (Dipartimento Politiche Antidroga—Drugs Policies Department, 2016).

In line with these data, Laudet et al. (2006) showed that the greatest concerns of individuals with SUD are about their future and ability to have a satisfactory quality of life. Redesigning, imagining, and planning for a satisfactory life after treatment, however, is not easy for individuals with SUD because of the many barriers they can experience. These barriers can be related to the "clients," such as low levels of education, lack of work experiences, unrealistic career goals, low levels of self-esteem, low levels of problem-solving skills, and low levels of decision making skills. The barriers can be also related to the "context," such as rigidity of treatment, prejudice against individuals with SUD in the work and family context, as well as poor social and family support (Richardson et al., 2012). Further barriers are associated with the current job market that is characterized by strong segmentation, unclear and serpentine career trajectories characterized by protean, customized, and kaleidoscopic pathways (Savickas et al., 2009). As indicated, individuals with SUD experience more disadvantages in the current labor market. Specifically, they are likely to be (a) recruited for low-skill jobs, especially because they have low levels of education, (b) to experience recurrent occupational transitions in poorly paid temporary jobs with few skill development opportunities and (c) their work situation is often precarious because their previous pre-SUD work and career experiences are not taken into consideration (Richardson et al., 2012).

The Life Design paradigm is a theoretical and practical perspective in the career and vocational field and was developed at the beginning of the economic crisis in twenty-first century. From this paradigm, attention should be given to those individuals who are more likely to become at-risk when dealing with today's job market and the work-employment/ re-employment processes (Nota et al., 2015a, b; Savickas et al., 2009). The challenge of this paradigm is to support individual's access to decent jobs and to increase their likelihood of experiencing satisfactory life conditions and professional realization (Ferrari et al., 2015). Career interventions contribute to this social challenge by promoting a set of psychological resources considered relevant in the life designing process, such as career adaptability, hope, resilience, future orientation (Nota et al., 2015a, b). Therefore, based on the Life Design paradigm, the aim of this study was to analyze the relation between career adaptability and hope (as two relevant resources for the life designing process) on life satisfaction in samples of individuals with and without SUD.

\subsection{Life Design Paradigm}

For many years, different models in vocational guidance have focused on finding the best fit among stable personality traits, personal characteristics, work environments, and occupations (e.g., Ferrari et al., 2015; Holland, 1997). Based on these theoretical frameworks, 
generally designed for individuals with a degree of choice in their lives (Blustein, 2001), studies and practices in vocational and career fields have been developed. Few scholars, however, have conducted studies and applied their theoretical frameworks to individuals with vulnerabilities, or developed interventions aimed at promoting these individuals' likelihood of experiencing satisfactory life conditions and career success (Blustein, 2001).

The Life Design paradigm offers a theoretical framework that can be used to understand the challenges of the current job market and provide specific career and life interventions for all individuals, with and without vulnerability (Savickas et al., 2009). The Life Design paradigm implements the theories of self-construction and career-construction, and considers five presuppositions about people in their life and work contexts: contextual possibilities, dynamic processes, non-linear progression, multiple perspectives, and personal patterns (Rossier, 2015; Savickas et al., 2009). The Life Design paradigm not only focuses on the work context but considers all aspects of people's lives simultaneously. In fact, work is seen as only "a slice of the pie" of people's broader life paths. This paradigm, therefore, aims to support individuals to reach an overall successful life, characterized by adaptive functioning and subjective well-being (Savickas et al., 2009).

\subsubsection{Career Adaptability}

Career adaptability represents a relevant resource for career and life design of people. It covers four resources: concern, control, confidence, and curiosity (Savickas \& Porfeli, 2012). Concern is the ability to project oneself into the future taking into account both what one is and what one would like to become. Control is the tendency to consider the future at least partially controllable. Curiosity is the propensity to explore the self, including skills, abilities, knowledge, and values, as well as consider the environment. Confidence is the belief in one's own ability to face challenges and overcome the obstacles and barriers that can be experienced in pursuing personal goals. Savickas and Porfeli (2012) assume that the four resources of career adaptability, predicted by dispositions (adaptivity), are positively related to adapting responses such as adaptive behaviors and beliefs that are used to deal with career development tasks and changing work and career conditions (e.g. resilience, decision making, hope). These behaviors and beliefs are hypothesized to mediate the association between career adaptability and adaptation results (such as life satisfaction, commitment, and work success).

The meta-analysis by Rudolph et al. (2017) provided empirical evidence to support Savickas and Porfeli's (2012) theory. The authors showed, based on a total of 90 studies, that career adaptability is significantly associated with measures of adaptivity (i.e., cognitive ability, big five traits, self-esteem), adapting responses (i.e., career planning, career exploration, occupational self-efficacy, and career decision-making self-efficacy), and adaptation results (i.e., career identity, calling, career/job/school satisfaction, job stress, employability).

The relationship between career adaptability and life satisfaction, conceptualized as an adaptation measure, has been tested in adults with vulnerabilities. Specifically, Ginevra et al. (2017b), examined parents of children with disabilities and showed that career adaptability is indirectly, through resilience (conceptualized as an adapting response), related to life satisfaction. Moreover, Santilli et al. (2014), examined 120 adults with mild intellectual disability and found that hope (also conceptualized as an adapting response) provided the indirect conduit between career adaptability and life satisfaction. 
Although the relevance of career adaptability in designing one's life has been largely recognized, we found no studies that have examined this dimension in individuals with SUD.

\subsubsection{Hope}

Hope has a number of scientific definitions in the literature. For example, Averill et al. (1990) considered hope as a cognitive construct as opposed to an emotion. Snyder (2000) defined hope as the individual's perception of his/her abilities to (1) clearly conceptualize goals, (2) plan the specific strategies to reach those goals (Pathways Thinking), and (3) initiate and sustain the motivation for using those strategies (Agency Thinking). Finally, Niles et al. (2011) emphasized the role of hope for career development because it allows one to envisage possibilities and encourages actions across different life situation.

Various researchers have shown that hope is related to positive health and work-related outcomes even in individuals with a vulnerability. For example, studies have highlighted that hope is associated with a wide range of indicators of psychosocial well-being, such as fewer behavioral problems, depressive symptoms, and higher levels of personal adaptation, adaptive achievement, and life satisfaction (Gilman et al., 2006; Kenny et al., 2010; Sheldon \& Hoon, 2013). Regarding the latter, Yaghoobzadeh et al. (2018) found that a person's ability to be hopefulness positively predicts life satisfaction, and more recently, Pahlevan Sharif et al. (2021) found that hope, with religiosity, fully mediated the relationship between close attachment and life satisfaction in older adults.

Regarding work outcomes, the meta-analysis conducted by Reichard et al. (2013) found that hope is positively related to various indicators and counter-indicators of well-being, including job satisfaction, organizational commitment, and employee health and wellbeing and negatively to employee burnout and stress. Moreover, Youssef and Luthans (2007) suggested that workers with higher levels of hope are likely to be more satisfied for their job because through hope they acquire both the motivation and the strategies for having career success.

The research on hope in substance abuse recovery has supported the idea that it is an important resource that can help individuals overcome recovery related challenges. Hope is critical for remaining abstinent for a long period. That is, the person must be aware of the means to achieve this goal and feel able to execute the relevant means. People with high levels of hope are more able to deal with situations that may compromise the goal of substance-abuse recovery, to develop strategies to overcome the factors that lead to a relapse and, in the case that this has occurred, strategies to resume the commitment to abstinence (Mathis et al., 2009).

At this regard, Irving et al. (1998) showed that hope was positively related to longer abstinence time and better quality of life. More recently, May et al. (2015) found that hope negatively predicted depressive and anxiety symptoms in individuals in recovery for SUD. Barbieri et al. (2016), examined 98 workers with SUD and showed that hope was positively correlated with future time perspective and resilience.

\subsubsection{Life Satisfaction}

Unlike different models in the vocational literature that focus attention on 'person-environment-fit', the Life Design paradigm considers quality of life, and in particular life satisfaction, as an important outcome in the vocational process (Rossier, 2015). Life satisfaction 
refers to a subjective component of the quality of life (Schalock \& Felce, 2004). Specifically, although it does not provide a multidimensional representation of quality of life, life satisfaction is commonly used because it refers to the subjective cognitive judgment that people express about their life (Pavot \& Diener, 1993; Schalock \& Felce, 2004).

In SUD research, life satisfaction is considered an important diagnostic and outcome criterion (Assari \& Jafari, 2010; Laudet et al., 2006; Rudolf \& Watts, 2002; Smith \& Larson, 2003). In fact, treatment for SUD aims for the broad goal of recovery, which is defined as abstinence plus improved life satisfaction (Laudet, 2011). Different studies showed that drug use is associated with low levels of life satisfaction and quality of life. Specifically, Ventegodt and Merrick (2003), showed that substance use is associated with lower quality of life and life satisfaction. Smith and Larson (2003), examined 570 individuals with SUD and showed that, compared to the general population or patients with a chronic illness, they reported lower levels of quality of life.

Brogly et al. (2003) found that life satisfaction is more prone to variations due to care interventions than the more objective life dimensions (such as housing, work, money, hospital admissions) in substance abuse clients.

\section{Aim of Study}

Given that no studies have currently examined career adaptability in adults with SUD and the relevance of career adaptability and hope for life satisfaction, the goal of this study is to analyze the relationship between career adaptability, hope, and life satisfaction in a samples of adults with and without SUD. Specifically, we analyze the invariance of the direct and indirect effects between career adaptability and life satisfaction, through hope, across both samples of individuals with and without SUD.

According to Rudolph et al.'s (2017) findings and Santilli et al.'s (2014) study, career adaptability is, directly and indirectly through the role of adaptive responses (e.g., hope), related to life satisfaction (adapting results). Therefore, we hypothesized that career adaptability would have both an indirect and direct effect on life satisfaction, through hope and, also, we expected these relationships would be invariant across the two samples.

\section{Method}

\subsection{Participants}

For the current study, participants were 185 adults with and 185 adults without SUD with about a 4 to 1 ratio of men to women (147 men and 38 women by group). Specifically, the adults with SUD were 39.70 years old $(\mathrm{SD}=10.18)$ and adults without SUD were 37.99 years old $(\mathrm{SD}=11.62)[t(368)=1.5 ; p=0.133]$. Participants with SUD had on overage 10.04 years of education $(\mathrm{SD}=2.88)$ and participants without SUD had 12.33 $(\mathrm{SD}=3.21)$ years of education $[t(368)=7.22 ; p<0.001]$. As regard to employment, 51 (27.6\%) participants without SUD were not working and 134 participants of same group (72.4\%) were working while $80(43.2 \%)$ participants with SUD were not working and 105 (56.8\%) participants of same group carrying out an internship within social cooperatives that, with public resources supports, are aimed at promoting social and work integration of people with SUD $\left[\chi_{(1)}^{2}=9.94 ; p=0.002\right]$. No further information on participants (such 
as socio-economic status) was available to the researchers. Regarding the adults with SUD, at the time of the study they were all in treatment for SUD in rehabilitation centers. Specifically, the participants reported to have a problem in substance use on average by 12.80 years $(\mathrm{SD}=9.85)$. As reported in the clinical records made available - with the consent of the participants-by the different rehabilitation centers involved in the research, it is showed as primary substance of use was multi-drug/or combined drug and alcohol among $61.1 \%$ (113 participants) and only alcohol among 38.9\% (72 participants).

\subsection{Measures}

The Career Adapt-Abilities Scale-Italian Form (CAAS-I; Soresi et al., 2012) consists of 24 items assessing four subscales: concern (e.g., "Realizing that today's choices shape my future"; $\alpha=0.80$ ), control (e.g. "Counting on myself"; $\alpha=0.74$ ), curiosity (e.g., "Investigating options before making a choice"; $\alpha=0.77$ ) and confidence (e.g. "Working up to my ability"; $\alpha=0.85)$. All 24 items comprise the career adaptability total score $(\alpha=0.91)$. Participants are asked to rate how much each statement describes their ability on a 5-point scale. Higher scores denoting higher levels of career adaptability. In a study carried out to adapt and validate the Italian version of the scale for adults, Nota, Ferrari et al. (2015) using confirmatory factor analysis (CFA) showed good internal consistency estimates (range 0.80-0.86) and acceptable fit indices for the original structural factor in Italian adults (Table 1 ).

The Adult Hope Scale (AHS-Snyder et al., 1991). The Adult Hope Scale has 12 items, with two subscales that comprise Snyder's cognitive model of hope: (1) Agency beliefs (4 items; e.g. "I energetically pursue my goals"; $\alpha=0.71$ ) and (2) Pathways thinking (4 items; e.g. "I can think of many ways to get the things in life that are important to me"; $\alpha=0.63$ ). Participants are asked to rate how much each statement describes them on a 4-point scale. Higher scores denoting higher levels of hope. In a study carried out to adapt and validate the Italian version of the scale, Soresi (2013) showed good internal consistency estimates for Agency $(\alpha=0.75)$ and Pathways $(\alpha=0.63)$ and acceptable fit indices $\left[\chi_{(19, \mathrm{n}=611)}^{2}=81.902 ; p<0.001 ; \mathrm{CFI}=0.974 ; \mathrm{NNFI}=0.952 ; \mathrm{RMSEA}=0.07{ }_{(0.06-0.09)}\right]$. In

Table 1 Distribution of demographic characteristics among the two groups

\begin{tabular}{|c|c|c|c|c|c|c|c|}
\hline \multicolumn{2}{|c|}{ Demographic variables } & \multicolumn{2}{|c|}{ Group without SUD } & \multicolumn{2}{|c|}{ Group with SUD } & \multirow[t]{2}{*}{$\chi^{2}$ test } & \multirow[t]{2}{*}{$t$ test } \\
\hline & & $\mathrm{F}(\%)$ & Mean (SD) & $\mathrm{F}(\%)$ & Mean (SD) & & \\
\hline Age & & & $37.99(11.62)$ & & $39.70(10.18)$ & & 1.5 \\
\hline $\begin{array}{l}\text { Years of } \\
\text { education }\end{array}$ & & & $12.33(3.21)$ & & $10.04(2.88)$ & & $7.22^{* *}$ \\
\hline \multirow[t]{2}{*}{ Sex } & Female & $38(20.5 \%)$ & & $38(20.5 \%)$ & & & \\
\hline & Male & $147(79.5 \%)$ & & $147(79.5 \%)$ & & - & \\
\hline \multirow{2}{*}{$\begin{array}{l}\text { Employment } \\
\text { State }\end{array}$} & Employee & $134(72.4 \%)$ & & $105(56.8 \%)^{\mathrm{a}}$ & & $9.94 * *$ & \\
\hline & Unemployed & $51(27.6 \%)$ & & $80(43.2 \%)$ & & & \\
\hline
\end{tabular}

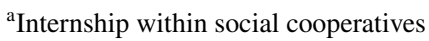

${ }^{* *} p$ value $<0.01$

${ }^{*} p$ value $<0.05$ 
this study, Cronbach's $\alpha$ s are 0.67 and 0.68 for the two subscales, and 0.79 for the total score.

The Satisfaction with Life Scale (SLS; Diener et al., 1985) consists of five items used to assess global life satisfaction. An example item is "I am satisfied with my life." Participants are asked to rate how much each statement describes them on a 7-point scale. Higher scores denote higher levels of life satisfaction $(\alpha=0.87)$. The Italian adaptation of the scale confirmed the mono-factorial structure, accounting for $55.73 \%$ of the total variance, and a good internal consistency ( $\alpha=0.80$; Di Maggio, 2014). Moreover, Di Maggio (2016) showed acceptable fit indices $\left[\chi_{(248 ; n=137)}^{2}=470.08 ; p<0.001 ; \mathrm{CFI}=0.945\right.$; $\left.\mathrm{NNFI}=0.943 ; \mathrm{RMSEA}=0.08_{(0.07-0.09)} ; \mathrm{SRMR}=0.07\right]$. In this study, $\alpha=0.83$.

\subsection{Procedure}

Individuals with SUD were identified by contacting rehabilitation centers for a project aimed to stimulate individuals with SUD to reflect on their future plans. Once selected, participants were contacted by a career counselor, who explained that the project aim was to foster reflection on future plans, and informed them that collected information would be protected by professional confidentiality, following ethical procedures approved by the Italian Ethical Principles of Psychologists and Italian Society for Vocational Guidance (SIO).

Adults without SUD were recruited from career guidance and vocational guidance activities organized by the La.R.I.O.S. laboratory (Laboratory for Research and Intervention in Vocational Designing and Career Counseling) at the University of Padova. The same ethical procedures of adults with SUD were following also for adults without SUD.

The assessment phase for the two groups, was conducted in the first phase of career project and lasted approximately $40 \mathrm{~min}$. At the end of assessment phase all participants received a personalized report of their individual results to reflect with career counselor about their future in individual career counseling activities.

\subsection{Data Analysis}

\subsubsection{Measurement Model Invariance}

We evaluated the measurement model (i.e., the relationship between manifest indicators and latent constructs) using a multi-group approach. To create the latent variables of career adaptability, hope, and life satisfaction, we used item parceling methods (see Little et al., 2002). For career adaptability and hope, the internal-consistency approach (Kishton \& Widaman, 1994) was used resulting in four parcels for career adaptability and two parcels for hope. For life satisfaction, a unidimensional construct, the item-to-construct balancing technique (Little et al., 2002) was used, creating two parcels.

To test for invariance of measurement model across groups a sequence of nested measurement models (i.e. configural invariance, weak invariance, and strong invariance; Little, 1997) using the maximum-likelihood estimation method (Quintana \& Maxwell, 1999) was executed. Configural invariance tests whether the basic model structure is equivalent among adults with and without SUD. Metric invariance verifies whether the factor loading parameters are invariant across groups. If a latent factor has equal loadings across groups, this guarantees that each group responds to the items in the same way (Cheung \& Rensvold, 2002). Finally, strong invariance, imposing equal intercepts of the regression equations of the observed variables on the latent factors. 
The following indices were used to evaluate the goodness of fit of the model: (a) the Root Mean Square Error of Approximation (RMSEA), (b) the Comparative Fit Index (CFI), (c) the non normed fit index (NNFI), and (d) the Standardized Root Mean Square Residual (SRMR). A model was considered to have an adequate fit if RMSEA was below 0.08 , CFI was 0.90 or more, NNFI was 0.90 or more, and SRMR was below 0.08 . In addition, to report the evidence of invariance, the change in the $\Delta$ CFI test was used (Chueng \& Rensvold, 2002; Little, 1997).

\subsubsection{Structural Model}

Multigroup structural analyses were conducted to test the group differences in the direct and indirect effects model hypothesized. This analysis is appropriate for this study because it evaluates between-group differences respect to the regression paths among career adaptability, hope, and life satisfaction. More specifically, two nested structural models were tested and compared: Model $\mathrm{A}_{0}$, where the relationship between career adaptability, hope and life satisfaction were hypothesized as free across groups; Model $\mathrm{A}_{1}$, where the relationships between career adaptability, hope and life satisfaction were hypothesized equal across groups.

Lastly, to test the magnitude and significance of relationship effects, we used a bootstrapping procedure (Shrout \& Bolger, 2002). Specifically, 1000 bootstrap samples from the original dataset through random sampling with replacement were formed. If the $95 \%$ confidence interval (CI) for the mean indirect effect does not include zero, the indirect effect is considered statistically significant at the 0.05 level.

\section{Results}

\subsection{Measurement Invariance}

The baseline model freely estimated for both groups, revealed a good fit $\chi_{(34 . n=360)}^{2}=64.907 ; p=0.001 ; \mathrm{CFI}=0.969 ; \mathrm{RMSEA}=0.070\left(\mathrm{CI}_{90}=0.044-0.096\right)$. As shown in Table 2, non-significant chi-square differences were observed between models when cross-group constraints were imposed on the models of configural and weak invariance. Moreover, CFI changes were less than 0.01 ( $\Delta$ CFI test; Cheung \& Rensvold, 2002), when cross-group constraints were imposed on the models. Regarding strong invariance, an omnibus test was carried out. The CFI changes test showed that strong invariance holds and examination of the latent means revealed significant differences across group (see Table 2). Specifically, people with SUD showed lower levels of career adaptability, hope, and life satisfaction respect to people without SUD (see Table 3). Finally, we also tested the effect of group on the regression paths by adding phantom constructs following Little (2013). The results showed that regression paths are equivalent between groups $\chi_{(3)}^{2}=6$ $0.57, p=0.08$ (see Table 4).

\subsection{Structural Mode Invariance}

The Model $\mathrm{A}_{0}$, where the direct and indirect relationship between career adaptability, hope and life satisfaction were hypothesized as free across groups showed adequate fit index $\chi_{(39, n=\mathrm{xxx})}^{2}=83.818, \mathrm{CFI}=0.961, \mathrm{RMSEA}=0.079, \mathrm{SRMR}=0.047$. However, 


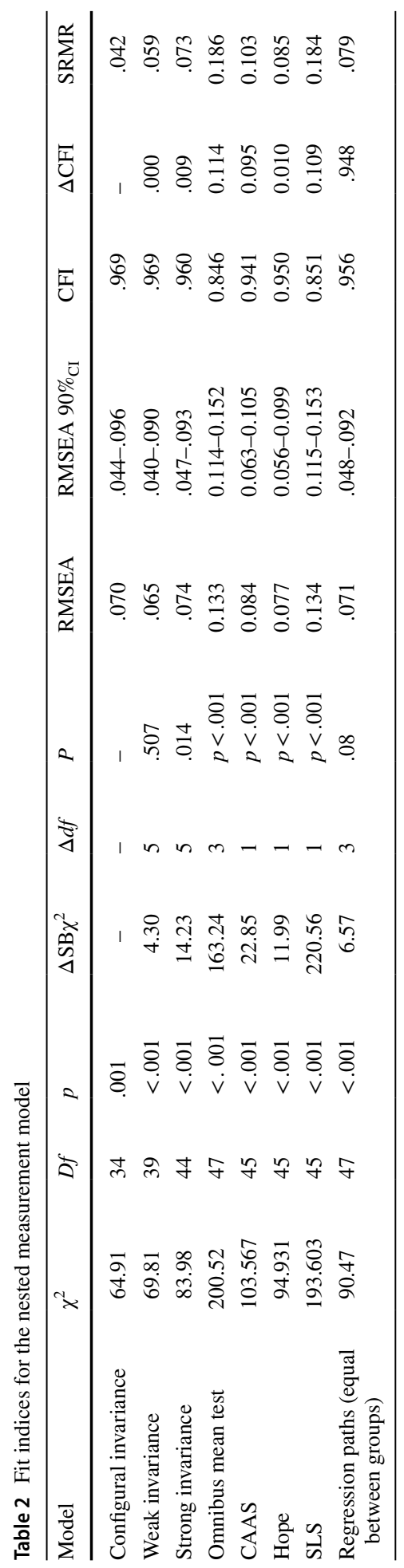


Table 3 Means and standard deviations among two groups

Table 4 Latent factor means by group

\begin{tabular}{|c|c|c|c|c|}
\hline \multirow[t]{2}{*}{ Study variables } & \multicolumn{2}{|c|}{ Group whit SUD } & \multicolumn{2}{|c|}{$\begin{array}{l}\text { Group without } \\
\text { SUD }\end{array}$} \\
\hline & M & SD & M & SD \\
\hline 1. Career adaptability & 148.52 & 16.53 & 117.66 & 14.16 \\
\hline 2. Hope & 24.36 & 4.18 & 25.72 & 3.25 \\
\hline 3. Life satisfaction & 16.50 & 5.91 & 23.57 & 5.54 \\
\hline
\end{tabular}

\begin{tabular}{lll}
\hline Latent factor & Group without SUD & Group with SUD \\
\hline CAAS & 0 & -0.491 \\
Hope & 0 & -0.373 \\
SLS & 0 & -1.396 \\
\hline
\end{tabular}

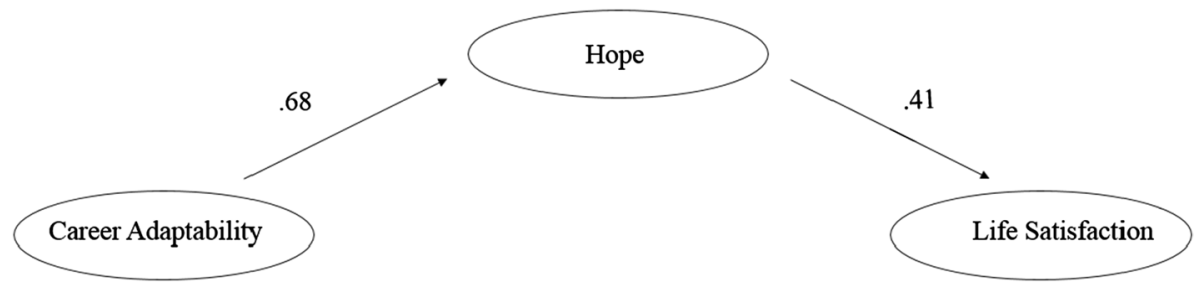

Fig. 1 Significant standardized parameters in the fully mediated model invariant across groups

the direct path from career adaptability to life satisfaction was not significant in both groups. Also the Model $\mathrm{A}_{1}$, where the direct and indirect paths between career adaptability, hope, and life satisfaction were hypothesized equal across group, showed adequate fit index $\chi_{(42, n=370)}^{2}=89.876, \mathrm{CFI}=0.959, \mathrm{RMSEA}=0.078, \mathrm{SRMR}=0.056$. Again, the direct path from career adaptability to life satisfaction was not significant for both groups. The chi-square difference test between the Model $\mathrm{A}_{0}$ and the Model $\mathrm{A}_{1}$, indicated that the Model $\mathrm{A}_{1}$ did not differ significantly from Model $\mathrm{A}_{0} \Delta \chi^{2}{ }_{(3)}=6.06$, $p>0.05$ and the invariant indirect effects model across two groups is supported.

Finally, the indirect and direct effects model across groups (Model $\mathrm{A}_{1}$ ) was compared with an indirect effect model only $\left(\right.$ Model $\left.\mathrm{B}_{1}\right)$. The indirect effect only model showed adequate fit indices: $\chi_{(43, n=370)}^{2}=90.839, \mathrm{CFI}=0.959$, RMSEA $=0.078$, $\mathrm{SRMR}=0.056$, and. the chi-square difference test between the Model $\mathrm{A}_{1}$ and the Model $\mathrm{B}_{1}$ indicated that the Model $\mathrm{B}_{1}$ did differ significantly from Model $\mathrm{A}_{1}$ $\Delta \chi_{(1)}^{2}=0.96, p>0.05$. Thus, the indirect effect only model, which was invariant across the two groups, was considered the final structural model (see Fig. 1).

The bootstrapping analysis highlighted that the bootstrap confidence interval for the indirect effect between career adaptability and life satisfaction through hope was between 0.179 and 0.458 , which indicates that the indirect effect is significantly different from zero. 


\section{Discussion}

Based on Life Design paradigm, the aim of this study was to test the relationship between career adaptability, hope and life satisfaction in adults with SUD compared to adults without SUD. Specifically, it was hypothesized that career adaptability predicted directly and indirectly, through hope, life satisfaction in individuals with and without SUD.

Using a multigroup approach across two samples of individuals with and without SUD, the results showed that career adaptability predicted life satisfaction only indirectly through hope. This pattern was invariant across groups, suggesting that although individuals with SUD perceived less career adaptability, hope, and life satisfaction than individuals with SUD, the relation between these dimensions was equal in the two groups.

Although these findings did not confirm Rudolph et al.'s (2017) and Santilli et al.'s (2014) studies about the direct role of career adaptability on life satisfaction, they were in line with other studies that emphasize only the indirect relationship between career adaptability and life satisfaction (e.g. Duffy et al., 2015; Ginevra et al., 2017b; Di Maggio et al., 2019). This result suggests that career adaptability influences the decision to start and maintain behaviors aimed at achieving goals (agency) and the plans for goal achievement (pathway) that lead to higher life satisfaction. A possible explanation may be that being characterized by a set of individual resources related to ability to project themselves into the future (concern), personal responsibility for own personal and professional experiences (control), propensity to explore the environment and the self (curiosity), and self-efficacy in own abilities to positively overcome and respond to stressful situations (confidence) may favor in individuals with and without SUD positive feelings to face difficulties and to succeed in what it is important for them (Scioli et al., 2011), thus stimulating even greater feelings of life satisfaction. Moreover, it is important to underline that the positive strong effect of career adaptability on hope (0.64), in line with previous studies (e.g., Santilli et al., 2014), can be connected to the fact that the two constructs, even if theoretically different, are intertwined as self-regulation processes that tend to positively project individuals into the future, to be goal-focused, to manage possible difficulties and barriers, to find alternative solutions, and to be proactive and flexible (Rossier, 2015; Vohs \& Schmeichel, 2002).

Overall, these results suggest that cognitions about life events, about difficulties and challenges encountered by individuals with SUD are more pertinent to psychological wellbeing than to the events themselves (Kashadan et al., 2002). Career adaptability and hope appear to be less influenced by stressful events, but they do carry the perception of being capable of projecting goals and planning strategies for reaching them, and thus show a positive effect on subjective quality of life.

This study has important theoretical and practical implications. The main theoretical implication is the examination of the role of relevant constructs for Life Design paradigm (i.e. career adaptability and hope) on life satisfaction in adults with SUD, considering that especially career adaptability has never been studied before in this population and in a comparison sample of non-SUD individuals. This study provided strong evidence of the contribution of career adaptability and hope in adults with SUD's life satisfaction. An additional theoretical implication is that ours study found two predictive resources for life satisfaction, that is believed to be an important diagnostic and outcome criteria in substance use disorder issues (Assari, \& Jafari, 2010; Laudet et al., 2006; Rudolf \& Watts, 2002; Smith \& Larson, 2003).

As regards the practical implication, the results obtained provide useful information to plan career interventions to increase life satisfaction in adults with SUD. Regarding career 
adaptability, career counselors could propose orientation activities to promote career concern; exercises of career decision making to promote career control, seeking-information activities to promote curiosity on self and the external environment; and use techniques such as modeling and vicarious learning to promote career confidence (Rossier, 2015).

Regarding hope, following Snyder's (2000) suggestions, career counselors could propose activities to help individuals to identify a list of future goals and to prioritize them in terms of importance. Once career counselors have helped individuals with SUD identify and rank their goals, they can work with them to develop their sense of agency and pathways. Specifically, they could support the individual's energy and motivation to pursue their goals, helping the, to monitor negative and discouraging thoughts and focusing on positive thoughts such as "I can do this" and "I'm a capable person". Finally, counselors could help individuals to develop subgoals that can be approached in a logical, step-by-step sequence and propose exercises aiming to find strategies to reach these goals (the "know how" cognition).

Besides individual career counseling (Duarte \& Cardoso, 2015), group life design interventions could be implemented to increase these resources (Rossier, 2015). At this regard, a recently career intervention developed by Ginevra et al. (2017a, b) could be used with adults with SUD. This career intervention, based on Life Design and tested with a sample of individuals at risk for the job market, aimed at fostering a series of resources to cope with career difficulty, to encourage reflecting on the future, to identify one's own strengths, and to plan future projects.

\subsection{Limitations and Directions for Future Studies}

There are some limitations associated with the present research that indicate possible areas for future studies. First, the participants were predominantly men. Although, this gender discrepancy reflects the rate of Italian users (86.2\% men; Dipartimento Politiche Antidroga-Drugs Policies Department, 2016), future studies could analyze the role of gender on dimensions considered. Secondly, no subgroup analyses based on primary substance or severity of the addiction were carried out. Future studies could analyze the role of different variables related to addiction such as type of primary drug use, severity of the addiction, comorbidity with psychatric disorder, and prison experiences. Moreover, in the structured model tested we included hope as a single latent factor because as reported in different studies agency and pathway components of hope are strongly related and operate in a combined process to provide hope (Luthans \& Jensen, 2002; Pattengale, 2009), despite this in the future studies could be interesting test the contribution of the single components of hope (agency and pathways) but also the contribution of other positive resources on personal and professional outcomes in individuals with SUD. Finally, in the studies we used a voluntary sampling methods for this reason the results obtained can be generalized only to people with SUD motivated to invest in a career intervention.

\section{Conclusions}

Adults with SUD are at high risk to be excluded in the job market and experience many barriers and challenges in designing and living a satisfactory life. This study provided a first contribution to literature about the role of career adaptability and hope, as two relevant resources for the life designing process, on individuals' with SUD life satisfaction, 
considered an important diagnostic and outcome criterion. Specifically, it highlighted that career adaptability is a significant resource for strengthening hope and, in turn, life satisfaction in individuals with and without SUD (e.g. Duffy et al., 2015; Ginevra et al., 2017b; Di Maggio, et al., 2019). This finding suggests that considering oneself able to construct own future career intentions and to handle career transitions may favor the ability to plan the specific strategies to reach future goals and initiate and sustain the motivation for using those strategies, thus stimulating life satisfaction (Pahlevan Sharif et al., 2021; Scioli et al., 2011; Yaghoobzadeh et al., 2018).

Funding Open access funding provided by Università degli Studi di Padova within the CRUI-CARE Agreement. None.

\section{Declarations}

Conflict of interest The authors declared that they have no conflict of interest.

Open Access This article is licensed under a Creative Commons Attribution 4.0 International License, which permits use, sharing, adaptation, distribution and reproduction in any medium or format, as long as you give appropriate credit to the original author(s) and the source, provide a link to the Creative Commons licence, and indicate if changes were made. The images or other third party material in this article are included in the article's Creative Commons licence, unless indicated otherwise in a credit line to the material. If material is not included in the article's Creative Commons licence and your intended use is not permitted by statutory regulation or exceeds the permitted use, you will need to obtain permission directly from the copyright holder. To view a copy of this licence, visit http://creativecommons.org/licenses/by/4.0/.

\section{References}

Abkhezr, P., McMahon, M., Glasheen, K., \& Campbell, M. (2017). Finding voice through narrative storytelling: An exploration of the career development of young African females with refugee backgrounds. Journal of Vocational Behavior. https://doi.org/10.1016/j.jvb.2017.09.007

Anderson, J. C., \& Gerbing, D. W. (1988). Structural equation modeling in practice: A review and recommended two-step approach. Psychological Bulletin, 103(3), 411-423. https://doi.org/10.1037/00332909.103.3.411

Assari, S., \& Jafari, M. (2010). Quality of life and drug abuse. In V. R. Preedy \& R. R. Watson (Eds.), Handbook of disease burdens and quality of life measures. (pp. 3691-3704). Springer.

Averill, J. R., Catlin, G., \& Chon, K. K. (1990). Rules of hope. Springer.

Barbieri, B., Dal Corso, L., Sipio, D., Maria, A., De Carlo, A., \& Benevene, P. (2016). Small opportunities are often the beginning of great enterprises: The role of work engagement in support of people through the recovery process and in preventing relapse in drug and alcohol abuse. Work, 55(2), 373-383. https://doi.org/10.3233/WOR-162411

Bernardi, L., Bollmann, G., Potarca, G., \& Rossier, J. (2017). Multidimensionality of well-being and spillover effects across life domains: How do parenthood and personality affect changes in domain-specific satisfaction? Research in Human Development, 14(1), 26-51. https://doi.org/10.1080/15427609.2016. 1268893

Blustein, D. L. (2001). Extending the reach of vocational psychology: Toward an inclusive and integrative psychology of working. Journal of Vocational Behavior, 59(2), 171-182. https://doi.org/10.1006/jvbe. 2001.1823

Brogly, S., Mercier, C., Bruneau, J., Palepu, A., \& Franco, E. (2003). Towards more effective public health programming for injection drug users: Development and evaluation of the injection drug user quality of life scale. Substance Use and Misuse, 38(7), 965-992. https://doi.org/10.1081/JA-120017619 
Byrne, B. M., \& Van de Vijver, F. J. (2010). Testing for measurement and structural equivalence in largescale cross-cultural studies: Addressing the issue of nonequivalence. International Journal of Testing, 10(2), 107-132. https://doi.org/10.1080/15305051003637306

Cheung, G. W., \& Rensvold, R. B. (2002). Evaluating goodness-of-fit indexes for testing measurement invariance. Structural Equation Modeling, 9(2), 233-255. https://doi.org/10.1207/S15328007S EM0902_5

Di Maggio, I. (2014). Nuove dimensioni e nuovi strumenti per l'orientamento precoce [New constructs and new instruments for the vocational prevention]. Paper presented at the seminar "Insegnare a pensare al futuro e al lavoro nella scuola dell'obbligo", Padova.

Di Maggio, I. (2016). Progettazione professionale e vulnerabilità: Il ruolo di alcune risorse di Life Design in persone con Disturbo da Uso di Sostanza [Life Design and Vulnerability: The role of some life design resources in people with Substance Use Disorder]. Paper presented at the Conference "XVI Convegno SIO-Società Italiana Orientamento", Milano.

Di Maggio, I., Shogren, K. A., Wehmeyer, M. L., Nota, L., \& Sgaramella, T. M. (2019). Career adaptability, self-determination, and life satisfaction: a mediational analysis with people with substance use disorder. Journal of Career Development, 0894845319847006. https://doi.org/10.1177/08948 45319847006

Diener, E. D., Emmons, R. A., Larsen, R. J., \& Griffin, S. (1985). The satisfaction with life scale. Journal of Personality Assessment, 49(1), 71-75. https://doi.org/10.1207/s15327752jpa4901_13

Dipartimento Politiche Antidroga - Drugs Policies Department. (2016). Relazione sui dati relativi allo stato delle tossicodipendenze in Italia [Report on data on drug dependence in Italy]. Retrieved from http:// www.emcdda.europa.eu/publications/edr/trends-developments/2013_en.

Duarte, M. E., \& Cardoso, P. (2015). The life design paradigm-From practice to theory. In L. Nota \& J. Rossier (Eds.), Life design handbook. (pp. 41-58). Hogrefe.

Duffy, R. D., Douglass, R. P., \& Autin, K. L. (2015). Career adaptability and academic satisfaction: Examining work volition and self efficacy as mediators. Journal of Vocational Behavior, 90, 46-54. https:// doi.org/10.1016/j.jvb.2015.07.007

European Observatory on Drugs. (2013). European drug report 2013: Trends and developments. Retrieved from http://www.emcdda.europa.eu/publications/edr/trends-developments/2013_en.

European Observatory on Drugs. (2017). European drug report 2017: Trends and developments. Retrieved from http://www.emcdda.europa.eu/system/files/publications/4541/TDAT17001ITN.pdf_en.

Ferrari, L., Sgaramella, M. T., \& Soresi, S. (2015). Bridging disability and work-contribution and challenges of life design. In L. Nota \& J. Rossier (Eds.), Handbook of life design: From practice to theory and from theory to practice. (pp. 219-232). Hogrefe Publishing.

Foster, J. H., Marshall, E. J., \& Peters, T. J. (2000). Application of a quality of life measure, the life situation survey (LSS) to alcohol dependent subjects in relapse and remission. Alcoholism Clinical and Experimental Research, 24(11), 1687-1692

Gilman, R., Dooley, J., \& Florell, D. (2006). Relative levels of hope and their relationship with academic and psychological indicators among adolescents. Journal of Social and Clinical Psychology, 25(2), 166-178. https://doi.org/10.1521/jscp.2006.25.2.166

Ginevra, M. C., Di Maggio, I., Nota, L., \& Soresi, S. (2017a). Stimulating resources to cope with challenging times and new realities: Effectiveness of a career intervention. International Journal for Educational and Vocational Guidance, 17(1), 77-96. https://doi.org/10.1007/s10775-016-9331

Ginevra, M. C., Di Maggio, I., Santilli, S., Sgaramella, T. M., Nota, L., \& Soresi, S. (2017b). Career adaptability, resilience, and life satisfaction: A mediational analysis in a sample of parents of children with mild intellectual disability. Journal of Intellectual and Developmental Disability. https://doi.org/10. 3109/13668250.2017.1293236

Gustavson, D. E., Stallings, M. C., Corley, R. P., Miyake, A., Hewitt, J. K., \& Friedman, N. P. (2017). Executive functions and substance use: Relations in late adolescence and early adulthood. Journal of Abnormal Psychology, 126(2), 257-270. https://doi.org/10.1037/abn0000250

Hair, J. F., Ringle, C. M., \& Sarstedt, M. (2011). PLS-SEM: Indeed a silver bullet. Journal of Marketing Theory and Practice, 19(2), 139-152. https://doi.org/10.2753/MTP1069-6679190202

Hira-Friesen, P. (2017). The effect of labour market characteristics on Canadian immigrant employment in precarious work 2006-2012. Canadian Journal of Urban Research, 26(1), 1-15

Holland, J. L. (1997). Making vocational choices: A theory of vocational personalities and work environments. (3rd ed.). Prentice Hall.

Irving, L. M., Seidner, A. L., Burling, T. A., Pagliarini, R., \& Robbins-Sisco, D. (1998). Hope and recovery from substance dependence in homeless veterans. Journal of Social and Clinical Psychology, 17(4), 389-406. https://doi.org/10.1521/jscp.1998.17.4.389 
Kashdan, T. B., Pelham, W. E., Lang, A. R., Hoza, B., Jacob, R. G., Jennings, J. R., \& Gnagy, E. M. (2002). Hope and optimism as human strengths in parents of children with externalizing disorders: Stress is in the eye of the beholder. Journal of Social and Clinical Psychology, 21(4), 441-468. https://doi.org/10. 1521/jscp.21.4.441.22597

Kenny, M. E., Walsh-Blair, L. Y., Blustein, D. L., Bempechat, J., \& Seltzer, J. (2010). Achievement motivation among urban adolescents: Work hope, autonomy support, and achievement-related beliefs. Journal of Vocational Behavior, 77(2), 205-212. https://doi.org/10.1016/j.jvb.2010.02.005

Kishton, J. M., \& Widaman, K. F. (1994). Unidimensional versus domain representative parceling of questionnaire items: An empirical example. Educational and Psychological Measurement, 54(3), 757-765

Laudet, A. B. (2011). The case for considering quality of life in addiction research and clinical practice. Addiction Science and Clinical Practice, 6(1), 44-45

Laudet, A. B., Morgen, K., \& White, W. L. (2006). The role of social supports, spirituality, religiousness, life meaning and affiliation with 12-step fellowships in quality of life satisfaction among individuals in recovery from alcohol and drug problems. Alcoholism Treatment Quarterly, 24(1-2), 33-73. https:// doi.org/10.1300/J020v24n01_04

Little, T. D. (1997). Mean and covariance structures (MACS) analyses of cross-cultural data: Practical and theoretical issues. Multivariate Behavioral Research, 32(1), 53-76. https://doi.org/10.1207/s1532 7906mbr3201_3

Little, T. D. (2013). Longitudinal structural equation modeling. Guilford press.

Little, T. D., Cunningham, W. A., Shahar, G., \& Widaman, K. F. (2002). To parcel or not to parcel: Exploring the question, weighing the merits. Structural Equation Modeling, 9(2), 151-173. https:// doi.org/10.1207/S15328007SEM0902_1

Luthans, F., \& Jensen, S. M. (2002). Hope: A new positive strength for human resource development. Human Resource Development Review, 1(3), 304-322. https://doi.org/10.1177/1534484302013003

Mathis, G. M., Ferrari, J. R., Groh, D. R., \& Jason, L. A. (2009). Hope and substance abuse recovery: The impact of agency and pathways within an abstinent communal-living setting. Journal of Groups in Addiction and Recovery, 4(1-2), 42-50. https://doi.org/10.1080/15560350802712389

May, E. M., Hunter, B. A., Ferrari, J., Noel, N., \& Jason, L. A. (2015). Hope and abstinence self-efficacy: Positive predictors of negative affect in substance abuse recovery. Community Mental Health Journal, 51(6), 695-700. https://doi.org/10.1007/s10597-015-9888-y

Niles, S. G., Amundson, N. E., \& Neault, R. (2011). Career Flow: A Hope-Centered Approach to Career Development. Retrieved from http://74.127.41.67/docs/career_flow_flyer.pdf.

Nota, L., Ferrari, L., Sgaramella, T. M., \& Soresi, S. (2015a). Strumenti di assessment per l'orientamento con adulti [Assessment measures for vocational guidance with adults]. Paper presented at seminar 'Diversity and work'. Padova: University of Padova.

Nota, L., Ginevra, M. C., \& Santilli, L. (2015b). Life design and prevention. In L. Nota \& J. Rossier (Eds.), Life design handbook. (pp. 183-199). Hogrefe.

Pahlevan Sharif, S., Amiri, M., Allen, K. A., Sharif Nia, H., Khoshnavay Fomani, F., Hatef Matbue, Y., \& Waheed, H. (2021). Attachment: the mediating role of hope, religiosity, and life satisfaction in older adults. Health and Quality of Life Outcomes, 19(1), 57. https://doi.org/10.1186/ s12955-021-01695-y

Pattengale, J. (2009). The hope scale: A measurement of willpower and waypower. In: R. L. Swing (Ed.), Proving and improving. Tools \& techniques for improving thefirst college year (monograph 37), II. (pp. 157-160). Columbia, SC: USC, National Resource Center for the First-year Experience and Students in Transition.

Pavot, W., \& Diener, E. (1993). Review of the satisfaction with life scale. Psychological Assessment, 5(2), 164-172. https://doi.org/10.1037/1040-3590.5.2.164

Quintana, S. M., \& Maxwell, S. E. (1999). Implications of recent developments in structural equation modeling for counseling psychology. The Counseling Psychologist, 27(4), 485-527

Reichard, R. J., Avey, J. B., Lopez, S., \& Dollwet, M. (2013). Having the will and finding the way: A review and meta-analysis of hope at work. The Journal of Positive Psychology, 8(4), 292-304. https://doi.org/10.1080/17439760.2013.800903

Richardson, L., Wood, E., Montaner, J., \& Kerr, T. (2012). Addiction treatment-related employment barriers: The impact of methadone maintenance. Journal of Substance Abuse Treatment, 43(3), 276-284. https://doi.org/10.1016/j.jsat.2011.12.008

Rossier, J. (2015). Career adaptability and life designing. In L. Nota \& J. Rossier (Eds.), Life design handbook. (pp. 156-168). Hogrefe.

Rudolf, H., \& Watts, J. (2002). Quality of life in substance abuse and dependency. International Review of Psychiatry, 14(3), 190-197. https://doi.org/10.1080/09540260220144975 
Rudolph, C. W., Lavigne, K. N., \& Zacher, H. (2017). Career adaptability: A meta-analysis of relationships with measures of adaptivity, adapting responses, and adaptation results. Journal of Vocational Behavior, 98, 17-34. https://doi.org/10.1016/j.jvb.2012.01.009

Santilli, S., Nota, L., Ginevra, M. C., \& Soresi, S. (2014). Career adaptability, hope and life satisfaction in workers with intellectual disability. Journal of Vocational Behavior, 85(1), 67-74. https://doi. org/10.1016/j.jvb.2014.02.011

Satorra, A., \& Bentler, P. M. (2001). A scaled difference chi-square test statistic for moment structure analysis. Psychometrika, 66(4), 507-514

Savickas, M. L., \& Porfeli, E. J. (2012). Career adapt-abilities scale: Construction, reliability, and measurement equivalence across 13 countries. Journal of Vocational Behavior, 80(3), 661-673. https:// doi.org/10.1016/j.jvb.2012.01.011

Savickas, M. L., Nota, L., Rossier, J., Dauwalder, J. P., Duarte, M. E., Guichard, J., \& Van Vianen, A. E. (2009). Life designing: A paradigm for career construction in the 21 st century. Journal of Vocational Behavior, 75(3), 239-250. https://doi.org/10.1016/j.jvb.2009.04.004

Schalock, R. L., \& Felce, D. (2004). Quality of life and subjective well-being: Conceptual and measurement issues. In E. Emerson, C. Hatton, T. Thompson, \& T. Parmenter (Eds.), International handbook of applied research in intellectual disabilities. (pp. 261-279). Wiley.

Scioli, A., Ricci, M., Nyugen, T., \& Scioli, E. R. (2011). Hope: Its nature and measurement. Psychology of Religion and Spirituality, 3(2), 78-97. https://doi.org/10.1037/a0020903

Sheldon, K. M., \& Hoon, T. H. (2013). The multiple determination of well-being: Independent effects of positive traits, needs, goals, selves, social supports, and cultural contexts. In A. Delle Fave (Ed.), The exploration of happiness (pp. 141-160). Retrieved from https://doi.org/10.1007/978-94-007-5702-8_1.

Shepard, D., \& Reif, S. (2004). The value of vocational rehabilitation in substance user treatment: A costeffectiveness framework. Substance Use Misuse, 39, 2581-2609. https://doi.org/10.1081/JA-20003 4732

Shrout, P. E., \& Bolger, N. (2002). Mediation in experimental and nonexperimental studies: New procedures and recommendations. Psychological Methods, 7(4), 422-445. https://doi.org/10.1037//1082-989X.7. 4.422

Smith, K. W., \& Larson, M. J. (2003). Quality of life assessments by adult substance abusers receiving publicly funded treatment in Massachusetts. The American Journal of Drug and Alcohol Abuse, 29(2), 323-335. https://doi.org/10.1081/ADA-120020517

Snyder, C. R. (2000). Handbook of hope: Theory, measures, and applications. Academic press.

Snyder, C. R., Harris, C., Anderson, J. R., Holleran, S. A., Irving, L. M., Sigmon, S. T., \& Harney, P. (1991). The will and the ways: Development and validation of an individual-differences measure of hope. Journal of Personality and Social Psychology, 60(4), 570-585. https://doi.org/10.1037/0022-3514.60.4.570

Soresi, S. (2013). Helping people build their future. Plenary session presented at the International Conference Life Design and career counseling building hope and resilience. Padova: University of Padova.

Soresi, S., Nota, L., \& Ferrari, L. (2012). Career Adapt-Abilities Scale-Italian Form: Psychometric properties and relationships to breadth of interests, quality of life, and perceived barriers. Journal of Vocational Behavior, 80(3), 705-711

Ventegodt, S., \& Merrick, J. (2003). Psychoactive drugs and quality of life. The Scientific World Journal, 3 , 694-706. https://doi.org/10.1100/tsw.2003.57

Vohs, K., \& Schmeichel, B. (2002). What makes hope hopeful? The relationship between hope and selfregulation. Psychological Inquiry, 13(4), 318-321. Retrieved March 15, 2021, from http://www.jstor. org/stable/1448877.

Wehmeyer, M. L., Nota, L., Soresi, S., Shogren, K. A., Morningstar, M. E., Ferrari, L., Sgaramella, T. M., \& DiMaggio, I. (2019). A crisis in career development: Life designing and implications for transition. Career Development and Transition for Exceptional Individuals, 42(3), 179-187. https://doi.org/10. $1177 / 2165143417750092$.

Yaghoobzadeh, A., Gorgulu, O., Yee, B.-L., Wibisono, A. H., Pahlevan Sharif, S., Sharif, N. H., \& Allen, K. A. (2018). A model of aging perception in Iranian elders with effects of hope, life satisfaction, and socioeconomic status: a path analysis. Journal of the American Psychiatric Nurses Association, 24(6), 522-530. https://doi.org/10.1177/1078390317753676

Youssef, C. M., \& Luthans, F. (2007). Positive organizational behavior in the workplace: The impact of hope, optimism and resiliency. Journal of Management, 33, 774-800. https://doi.org/10.1177/01492 06307305562

Publisher's Note Springer Nature remains neutral with regard to jurisdictional claims in published maps and institutional affiliations. 